\title{
Recurrent hypoinsulinemic hyperglycemia in neonatal rats increases PARP-1 and NF-KB expression and leads to microglial activation in the cerebral cortex
}

\author{
Tate Gisslen ', Kathleen Ennis' ${ }^{1}$ Vineet Bhandari ${ }^{2,3}$ and Raghavendra Rao'
}

BACKGROUND: Hyperglycemia is a common metabolic problem in extremely low-birth-weight preterm infants. Neonatal hyperglycemia is associated with increased mortality and brain injury. Glucose-mediated oxidative injury may be responsible. Poly(ADP-ribose) polymerase-1 (PARP-1) is a nuclear enzyme involved in DNA repair and cell survival. However, PARP-1 overactivation leads to cell death. NF-KB is coactivated with PARP-1 and regulates microglial activation. The effects of recurrent hyperglycemia on PARP-1/NF-KB expression and microglial activation are not well understood.

METHODS: Rat pups were subjected to recurrent hypoinsulinemic hyperglycemia of $2 \mathrm{~h}$ duration twice daily from postnatal (P) day 3-P12 and killed on P13. mRNA and protein expression of PARP-1/NF-KB and their downstream effectors were determined in the cerebral cortex. Microgliosis was determined using CD11 immunohistochemistry.

RESULTS: Recurrent hyperglycemia increased PARP-1 expression confined to the nucleus and without causing PARP-1 overactivation and cell death. NF-KB mRNA expression was increased, while I KB mRNA expression was decreased. inducible nitric oxide synthase (iNOS), endothelial nitric oxide synthase (eNOS), and neuronal nitric oxide synthase (nNOS) mRNA expressions were decreased. Hyperglycemia significantly increased the number of microglia.

CONCLUSION: Recurrent hyperglycemia in neonatal rats is associated with upregulation of PARP-1 and NF-KB expression and subsequent microgliosis but not neuronal cell death in the cerebral cortex.

$\mathrm{H}$ yperglycemia is a common metabolic problem in preterm infants and especially frequent in extremely low-birthweight (ELBW) infants (1). Several mechanisms contribute to hyperglycemia in these infants. These include aggressive glucose infusion rates, an inability to inhibit hepatic gluconeogenesis, relative hypoinsulinism, and decreased insulin receptors in peripheral tissues (2). Neonatal hyperglycemia is associated with increased risk of death, intraventricular hemorrhage, sepsis, and worse outcomes in cases of necrotizing enterocolitis (2-4). Neonatal hyperglycemia also leads to long-term growth deficits lasting at least until $2 \mathrm{y}$ of age (5).

The long-term neurodevelopmental effects of hyperglycemia in ELBW infants are not well understood. In children with type 1 diabetes, poorly controlled hyperglycemia is postulated to be responsible for cognitive and developmental deficits (6). Limited data suggest that neonatal hyperglycemia may also lead to neurodevelopmental deficits (7). Multiple molecular mechanisms of glucose-mediated neurologic injury have been implicated; among which, superoxide overproduction via the mitochondrial electron-transport chain is the common link. Superoxides and nitrogen-based free radicals form peroxynitrate that can cause DNA strand breakage and activate poly(ADP-ribose) polymerase-1 (PARP-1) (8). PARP-1 is a nuclear enzyme involved in cell survival by binding to DNA breakage sites and poly(ADP-ribosyl)ation (PAR) of DNA repair proteins such as DNA ligases, polymerases, and histones in a $\mathrm{NAD}^{+}$dependent manner (9). However, excess PARP-1 activation can lead to cell death via $\mathrm{NAD}^{+}$depletion and PARmediated release of apoptosis inducing factor from the mitochondria (10).

PARP-1 is also a coactivator of nuclear factor $\kappa B(N F-\kappa B)$, a transcription factor with regulatory roles in immune function and inflammation. Under normal conditions, NF- $\kappa B$ regulates a healthy immune system and its dysregulation is implicated in inflammatory disease and cancer (11). NF- $\mathrm{KB}$ is bound by its inhibitor I $\kappa \mathrm{B}$ in the cytosol. Under stimulating signals, I $\mathrm{KB}$ gets phosphorylated and degraded, allowing NF- $\mathrm{KB}$ to translocate to the nucleus for transcription of target genes (12). Interaction between PARP-1 and NF- $\mathrm{KB}$ is implicated in the end-organ damage associated with diabetes mellitus. PARP and NF- $\kappa B$ activity are both increased in the blood of diabetic patients (13). Inhibition of either PARP or NF- $\mathrm{\kappa B}$ reverses the end-organ damage in a diabetic rodent model (14). PARP-1 and NF- $\kappa B$ interaction also induces microglial activation (15), revealing a potential inflammatory role for this pathway in the brain. 


\section{Articles $\mid$ Gisslen et al.}

Rodent models of diabetes mellitus demonstrate increased PARP-1 activation and DNA damage in the brain $(16,17)$. The effects of neonatal hyperglycemia on PARP-1/NF-KB activation in the developing brain and its role in brain injury are unknown. How they interact with the microglia under hyperglycemic conditions is also unknown. We hypothesized that recurrent hyperglycemia during the early postnatal period would lead to PARP-1/NF- $\kappa B$ overactivation and result in brain injury. We focused on the cerebral cortex as its peak development occurs in the postnatal period (18), coinciding with the period of hyperglycemia. The high metabolic demand of peak development may increase the potential for oxidative stress due to hyperglycemia in this region.

\section{RESULTS}

Development of a Neonatal Model of Recurrent Hypoinsulinemic Hyperglycemia

Pilot studies were conducted comparing different doses of octreotide $(0-1,000 \mu \mathrm{g} / \mathrm{kg})$, and different doses (200$5,000 \mathrm{mg} / \mathrm{kg})$ and concentrations $(10,30$, and $50 \%)$ of dextrose in a separate set of $\mathrm{P} 3$ and $\mathrm{P} 12$ rat pups $(n=4-6$ per experimental condition). Administration of $3.5 \mathrm{mg} / \mathrm{g}$ dextrose $(0.012 \mathrm{ml}$ of $30 \%$ dextrose per g body weight) without octreotide preadministration caused hyperglycemia (blood glucose, $286 \pm 22 \mathrm{mg} / \mathrm{dl}$ ) and increased plasma insulin concentration at $1 \mathrm{~h}(1.84 \pm 0.50$ vs. $0.20 \pm 0.03 \mathrm{ng} / \mathrm{ml}$ in the control group, $P<0.01)$. Octreotide preadministration in a dose of $100 \mu \mathrm{g} / \mathrm{kg}$ prior to dextrose administration suppressed endogenous insulin secretion, but did not completely abolish it at $1 \mathrm{~h}$ (plasma insulin concentration, $0.54 \pm 0.13 \mathrm{ng} / \mathrm{ml}$ ) despite comparable hyperglycemia (blood glucose, $245 \pm 22 \mathrm{mg} / \mathrm{dl}$ ). At
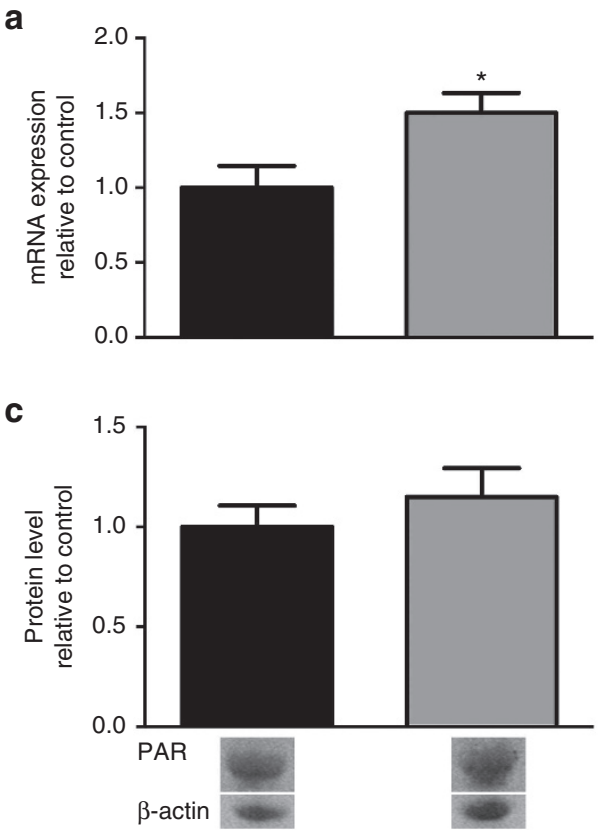

$2 \mathrm{~h}$, insulin levels in hyperglycemic animals with and without octreotide preadministration were comparable $(1.51 \pm 0.84$ vs. $1.36 \pm 0.59 \mathrm{ng} / \mathrm{ml}, P=0.8)$. Octreotide administration without dextrose did not cause hyperglycemia, nor affect plasma insulin concentration $(0.16 \pm 0.03 \mathrm{ng} / \mathrm{ml}$ at $1 \mathrm{~h}$ and $0.19 \pm 0.05 \mathrm{ng} /$ $\mathrm{ml}$ at $2 \mathrm{~h}$ ). Higher octreotide (500 and $1,000 \mu \mathrm{g} / \mathrm{kg}$ ) doses led to complete insulin suppression (plasma insulin below the detection level $(0.107 \mathrm{ng} / \mathrm{ml})$ and extreme hyperglycemia $(498 \pm 32 \mathrm{mg} / \mathrm{dl})$. Hence, a $100 \mu \mathrm{g} / \mathrm{kg}$ octreotide dose was used in the experiments.

\section{Blood Glucose Concentrations in Experimental Animals}

Blood glucose concentration was measured at 1 and $2 \mathrm{~h}$ following dextrose dosing to confirm hyperglycemia. The hyperglycemia group had higher glucose concentrations than the control group at both time points (blood glucose concentration (mg/dl): $210 \pm 15$ vs. $147 \pm 4$ at $1 \mathrm{~h}$, and $217 \pm 17$ vs. $128 \pm 2$ at $2 \mathrm{~h}(P<0.001))$. Blood glucose concentrations at $3 \mathrm{~h}$ were comparable in the two groups ( $134 \pm 5$ vs. $121 \pm 7(P=0.18)$ ). Hyperglycemia did not affect weight gain (body weight on P13: Control group, $32.0 \pm 0.8 \mathrm{~g}$; Hyperglycemia group, $32.0 \pm 0.8 \mathrm{~g}$ ).

\section{Effect of Hyperglycemia on PARP-1 and NF-kB}

PARP-1 and NF- $\kappa B$ mRNA expression and protein levels were measured in the cerebral cortex to determine how they were affected by hyperglycemia. Hyperglycemic animals had 1.5-fold higher PARP-1 mRNA expression compared with the control animals (Figure 1a). There was no difference in the expression of poly (ADP ribose) glycohydrolase (PARG) mRNA, the enzyme responsible for the catabolism of PAR polymers in cytoplasm (Figure 1b). The levels of PAR polymers
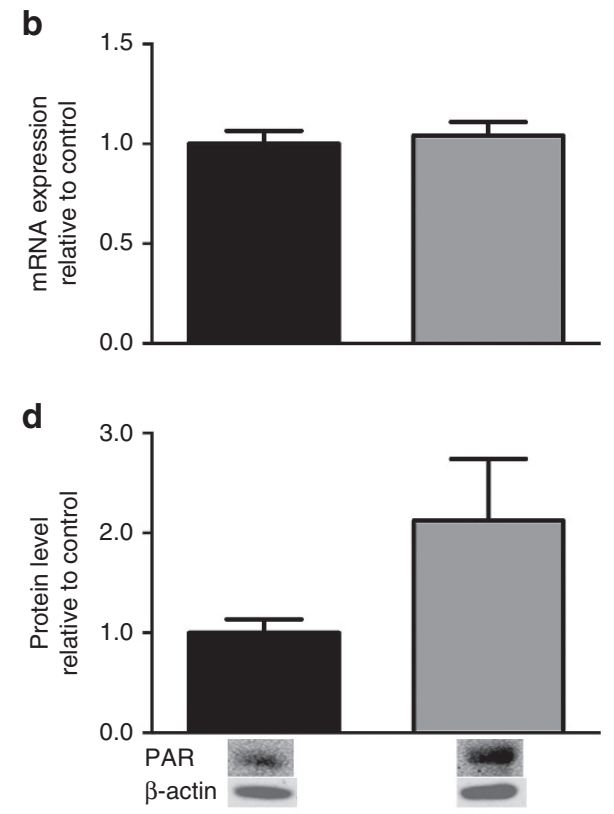

Figure 1. Effect of recurrent hyperglycemia on Poly(ADP-ribose) polymerase-1 (PARP-1) expression. (a) PARP-1 mRNA expression was increased by 1.5fold in recurrent hyperglycemia group (gray bars) over control group (black bars) $\left.{ }^{*} P<0.05\right)$. (b) Poly(ADP-ribose) glycohydrolase (PARG) $m R N A$ expression did not change. (c) Cytosolic PAR polymers did not change. (d) Nuclear poly(ADP ribose) (PAR) polymers were increased by 2.1 -fold, although it was not significant $(P=0.11)$. Representative western blots of PAR relative to control $\beta$-actin are shown. 
were assayed separately in the cytoplasm and nuclear fractions. There was no difference in PAR polymer level in the cytoplasm $(1.0 \pm 0.11$ vs. $1.15 \pm 0.14 ; P=0.71)$ (Figure 1c). There was a 2.1-fold increased PAR polymer in the nucleus, although it was not statistically significant $(1.0 \pm 0.14$ vs. $2.12 \pm 0.62$; $P=0.11$ ) (Figure 1d). Hyperglycemia upregulated the NF- $\kappa B$ mRNA expression 1.6-fold (Figure 2a). There were no changes in NF- $\kappa \mathrm{B}$ protein level in either the cytoplasm $(1.0 \pm 0.15$ vs. $0.97 \pm 0.05 ; P=0.87)$ or nucleus $(1.0 \pm 0.12$ vs. $0.99 \pm 0.10$; $P=0.97$ ) (Figure $2 \mathbf{b}, \mathbf{c}$ ). However, the expression of IKB mRNA, the inhibitor of NF- $\kappa \mathrm{B}$, was significantly decreased by $20 \%$ (Figure $2 \mathrm{~d}$ ) and there was a trend toward decreased cyto-

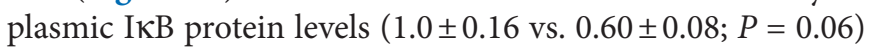
(Figure 2e).

\section{Effect of Hyperglycemia on Upstream and Downstream Effectors of PARP-1/NF-kB Expression}

The mRNA expression of tumor suppressor gene p53, which is activated by DNA damage, was increased in the hyperglycemia group (Table 1). Apoptosis inducing factor and caspase 3 mRNA expressions were not affected. The mRNA expression of the antiapoptotic, Bcl-2 was upregulated 1.8-fold.

Because NF- $\kappa \mathrm{B}$ is known to stimulate nitric oxide synthesis, we measured the mRNA expression of nitric oxide synthase (NOS), iNOS, eNOS, and nNOS in the cerebral cortex. All three were significantly decreased in the hyperglycemia group (Table 1).

\section{Effect of Hyperglycemia on Neuronal Cell Death and Microglial Activation}

Consistent with a lack of change in apoptotic factors, immunohistochemistry did not demonstrate increased neuronal cell death at $\mathrm{P} 13$ (15.2 \pm 1.7 vs. $16.3 \pm 2.6$ dead cells/slide, $P=0.74$ ). Microglia were quantified by immunostaining for CD11. The hyperglycemia group had significantly increased number of CD11-positive cells ( $281 \pm 17$ vs. $159 \pm 20$ cells $\left./ \mathrm{m}^{2}, P=0.003\right)$ (Figure 3c).

\section{DISCUSSION}

In our study of developing rats, recurrent hypoinsulinemic hyperglycemia led to significant upregulation in PARP-1 and NF- $\kappa \mathrm{B}$ mRNA expression in the cerebral cortex. This finding is consistent with previous studies of diabetic rats $(9,16,19)$. Hyperglycemia was also associated with reactive microgliosis, but without evidence of neuronal injury. These results demonstrate that recurrent hyperglycemia during development is associated with evidence of oxidative stress, DNA damage and inflammation, but not obvious neuronal injury.

PARP-1 has an important role in DNA repair: however during immense activation it leads to cell death through depletion
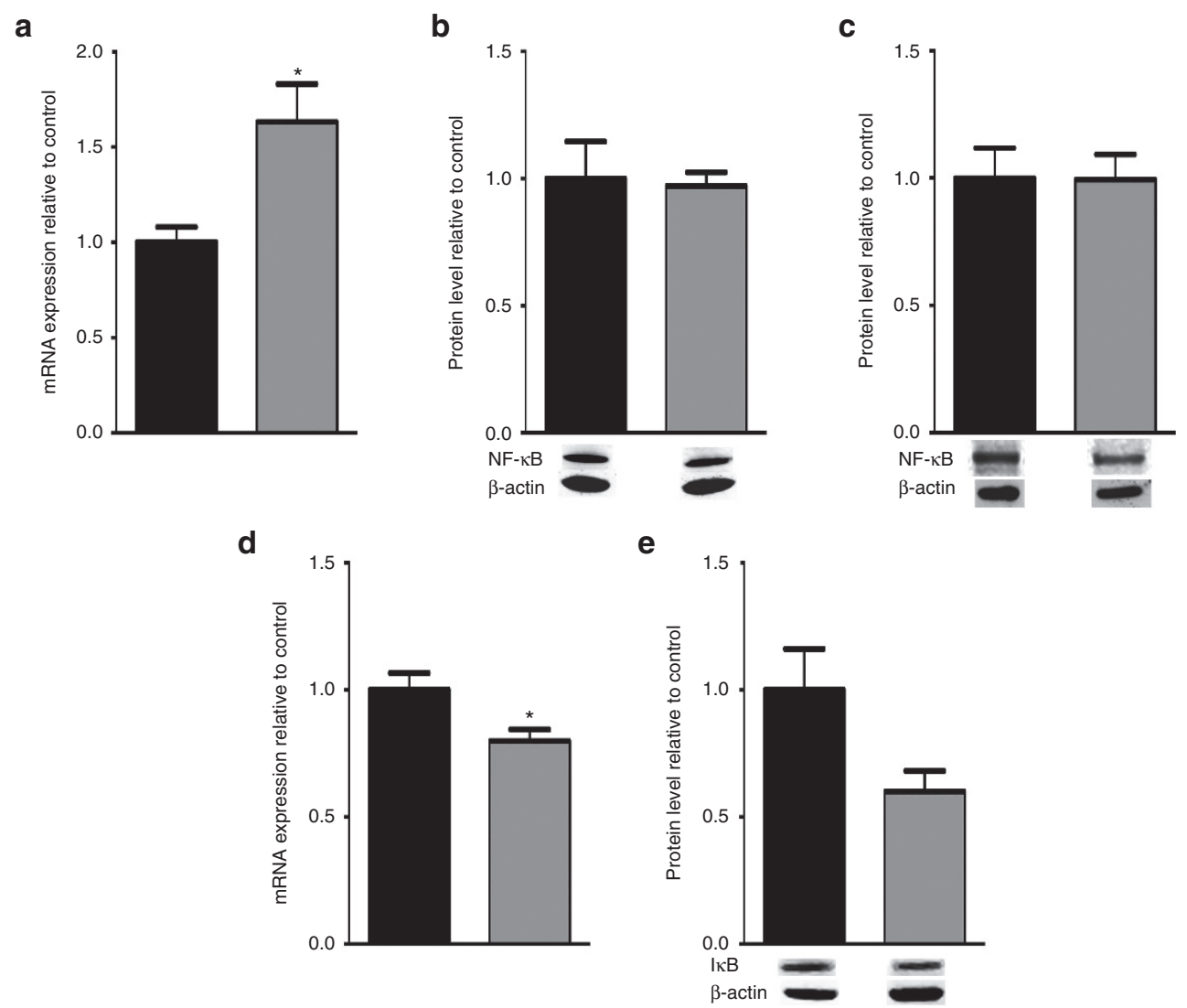

Figure 2. Effect of recurrent hyperglycemia on nuclear factor- $\kappa B(N F-\kappa B)$ expression. (a) NF- $\kappa B$ mRNA expression was significantly increased by 1.6-fold following recurrent hyperglycemia (gray bars) over control group (black bars) $\left({ }^{*} P<0.05\right)$. NF- $\mathrm{\kappa B}$ protein level in the cytosol (b) and nucleus (c) did not change due to recurrent hyperglycemia. (d) IKB mRNA expression decreased by $20 \%$ following hyperglycemia $\left({ }^{*} P<0.05\right)$. (e) I $\mid \kappa B$ cytosol protein level decreased by $40 \%$, however it was not significant $(P=0.06)$. Representative western blots of NF-KB and IKB relative to control $\beta$-actin are shown. 


\section{Articles | Gisslen et al.}

of $\mathrm{NAD}^{+}$and subsequent activation of apoptosis inducing factor and caspase enzymes $(10,20)$. Despite increased PARP-1 activity in our model of hyperglycemia, neonatal rats did not exhibit increased neuronal death nor was there a significant difference of mRNA expression of apoptosis inducing factor or caspase. Additionally, there was upregulation of mRNA expression of the antiapoptotic enzyme Bcl-2. Collectively, these results suggest that unlike the diabetic brain (or mature brain as the case may be), the neonatal brain may be able to withstand hyperglycemia without sustaining injury, despite the occurrence of the oxidative stress demonstrated in a similar model (21). One potential mechanism may be the higher concentration of low molecular weight antioxidants, alpha tocopherol, ascorbate, and glutathione in the developing brain regions, relative to the mature brain, that may reduce the risk of injury (22). In this setting, PARP-1 upregulation may reflect an attempt at repairing any minor DNA breaks. The PAR polymer upregulation confined to the nucleus is consistent with this possibility. Lack of changes in cytosolic PAR polymers and PARG mRNA, the enzyme responsible for degrading PAR in the cytoplasm, further support that PARP-1 upregulation is confined to the nucleus and represents a physiological response in the present study.

Consistent with a previous report (23), PARP-1 mRNA upregulation was associated with increased NF- $\mathrm{KB}$ expression

Table 1. Relative mRNA expression of upstream and downstream effectors of PARP-1/NF-kB expression

\begin{tabular}{lcc}
\hline Transcript & $\begin{array}{c}\text { Control } \\
\text { group }\end{array}$ & $\begin{array}{c}\text { Hyperglycemia } \\
\text { group }\end{array}$ \\
\hline P53 & $1.00 \pm 0.04$ & $1.23 \pm 0.08^{*}$ \\
Caspase 3 & $1.00 \pm 0.09$ & $1.40 \pm 0.16$ \\
Apoptosis inducing factor & $1.00 \pm 0.27$ & $1.12 \pm 0.16$ \\
Bcl-2 & $1.00 \pm 0.11$ & $1.76 \pm 0.13^{*}$ \\
iNOS & $1.00 \pm 0.10$ & $0.23 \pm 0.01^{*}$ \\
eNOS & $1.00 \pm 0.08$ & $0.61 \pm 0.05^{*}$ \\
nNOS & $1.00 \pm 0.05$ & $0.48 \pm 0.04^{*}$ \\
\hline
\end{tabular}

Values are mean $\pm \operatorname{SEM}(n=5-7)$.

${ }^{*} P<0.05$ control vs. hyperglycemia groups. in the cortex of hyperglycemic neonatal rats. Vascular endothelial dysfunction leading to nephropathy, retinopathy, angiopathy, and peripheral neuropathy in diabetes occurs through combined PARP-1/NF- $\mathrm{KB}$ pathways $(13,14,16)$. NF- $\mathrm{KB}$ is an important transcription factor in multiple pathways, including the production of cytokines and NOS, which then lead to apoptosis and cell death $(24,25)$. However, such an effect was not seen in our study. Despite increased NF- $\kappa B$, we found decreased NOS. Hyperglycemia inhibits eNOS through multiple mechanisms $(26,27)$. NF- $\mathrm{KB}$ may also have an anti-inflammatory and antiapoptotic role in the brain during development. Yang et al. (28) showed that NF- $\mathrm{KB}$ during the neonatal period, compared with the adulthood, is more important for cell survival in the lung during hyperoxia. They found downregulation of I $\mathrm{KB}$ and upregulation of Bcl-2 expression in neonatal mice, consistent with our findings in the developing cerebral cortex during hyperglycemia. Importantly, the role of NF- $\mathrm{KB}$ during hyperglycemia-induced oxidative stress may be different during development than during adulthood. We propose a mechanism illustrating the differences between neonatal and adult hyperglycemia (Figure 4).

Although hyperglycemic neonatal rats did not exhibit cortical neuronal death, they showed signs of potential disease. We found a significant increase of cortical microglia activation in hyperglycemic animals. Microglia are known to have dueling roles, either protective, by acting as a phagocyte and removing debris and facilitating tissue repair, or cytotoxic, as in stroke models where neurons surviving initial hypoxiaischemia experience secondary damage due to release of toxins by microglia $(29,30)$. PARP- 1 and NF- $\kappa B$ are involved in the regulation of microglial activation and function (15).

Microglia may be beneficial in the case of hyperglycemic neonatal rats. In an ischemic stroke rat model, Madinier et al demonstrated that decreased microglial activation was associated with decreased tissue brain derived neurotrophic factor (BDNF) expression (31). PARP-1 was inhibited to dampen the microglial response to hypoxia-ischemia, but it resulted in a dampened response of BDNF in the infarct zone. They also showed decreased expression of the intracellular neuronal growth protein GAP-43 and synaptophysin, an integral membrane protein of synaptic vesicles and a marker of
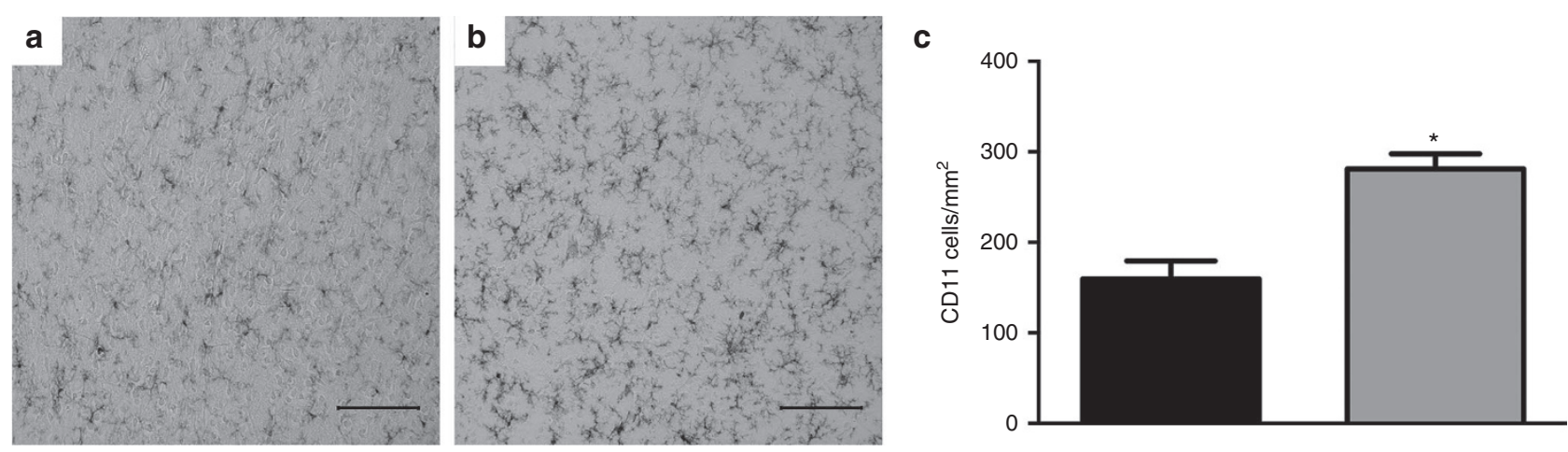

Figure 3. Effect of recurrent hyperglycemia on microgliosis. Representative photomicrographs of the cerebral cortex from (a) control and (b) recurrent hyperglycemia groups stained for CD-11. Scale bars represent $100 \mu \mathrm{m}$. (c) The number of CD-11-positive microglia were increased in the recurrent hyperglycemia group (gray bar) over the control group (black bar) $(* P<0.05)$. 


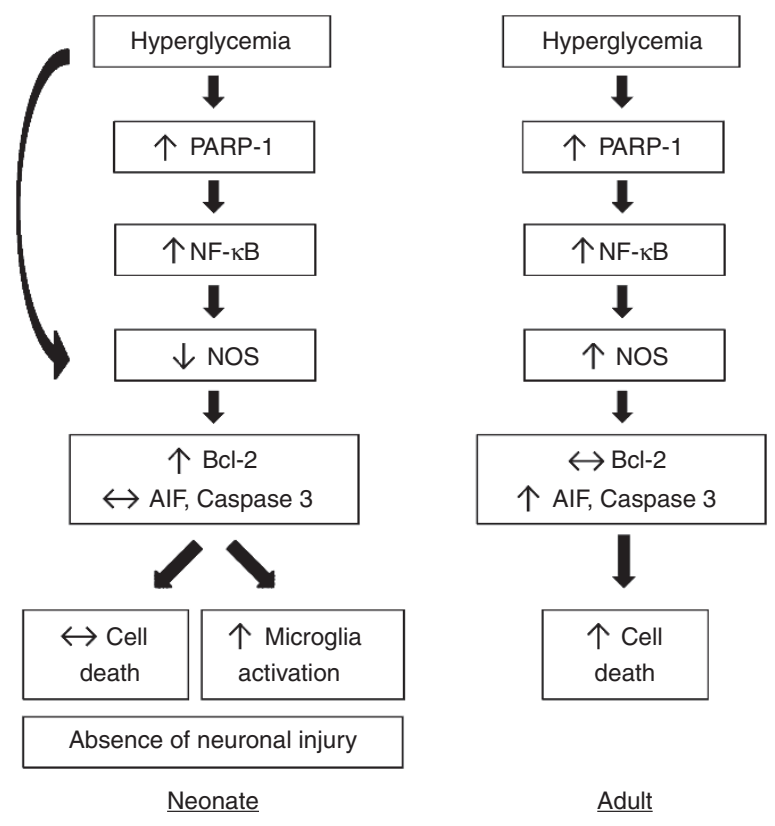

Figure 4. Proposed mechanism of hyperglycemia-induced brain injury in neonates and adults. AIF, apoptosis inducing factor; NOS, nitric oxide synthase.

synaptogenesis (31). Similarly, the increased microglia in our model may be a source for neurotrophic factors.

Neuroprotection with hyperglycemia may be age and sexdependent, and vary by the presence of comorbidities. Our group has previously shown that acute hypoglycemia leads to PARP-1 overactivation and cell death in adult rats, but not in developing rats (32). Additionally, the animals used in our study were all female. Hormonal differences between genders influence the effects of hyperglycemia (33). Likewise, PARP-1 is more neurotoxic in males than females (34). Thus, hyperglycemia may be more detrimental to males while the females were protected from neuronal injury. Finally, the absence of cell death in the present study does not rule out the possibility of other adverse effects (for example, on synaptogenesis) in the brain regions (35). In addition, we assessed cell death only at P13; we are unable to comment on changes occurring earlier or later than this time point. The results may also be altered in the setting of different severity, duration, and frequency of hyperglycemia than the one used in our study. Additional studies are necessary to address these limitations and before the results can be extrapolated to human newborns.

Hyperglycemia in the neonatal intensive care unit is a common problem, occurring in up to $80 \%$ of ELBW infants (3). Hyperglycemia is intermittent in ELBW infants, lasting 10-20\% $(2-5 \mathrm{~h})$ each day during the first $1-2 \mathrm{wk}$ after birth before it is controlled $(36,37)$. Our study attempted to model this phenomenon by altering metabolic pathways of a term gestation rat pup to determine the effect on the developing brain. How the brains of neonatal rats and humans utilize glucose is an important difference. Glucose is the primary energy substrate in a neonatal human brain. In contrast, the rat brain mainly utilizes ketones until maternal weaning. Glucose consumption increases gradually; levels at birth are only $3-5 \%$ of an adult and $\sim 30 \%$ at $10 \mathrm{~d}$
(38). The anatomy of neonatal rat and human cerebral cortices is also an important difference. However, due to similarities in the rate of postnatal brain growth, development pattern of the germinal matrix, and neurochemical data, P7-P14 is generally accepted to correspond to a term human brain (39). Our model of recurring hyperglycemia is meant to affect the premature rat brain $(<7 \mathrm{~d})$, but also include the period of rapidly increasing glucose utilization between P7 and P12. Despite evidence of hyperglycemia as a risk factor for poor outcomes in preterm infants, treatment of hyperglycemia is controversial because of the likelihood for hypoglycemia with insulin therapy (37). Therefore we sought more information on the long-term effects of hyperglycemia. To the best of knowledge, this is the first description of a novel model of recurrent neonatal hypoinsulinemic hyperglycemia. Acute hyperglycemia without blocking endogenous insulin secretion has the potential to result in fluctuating blood glucose levels and may cloud the results. Our model is unique in that it emulates hypoinsulinemia/insulin insensitivity and the dextrose infusions frequently required by neonates, thus mimicking the human condition. Hence, it has great potential for understanding pathophysiologic mechanisms of recurrent neonatal hyperglycemia.

In summary, we found that recurrent hyperglycemia in neonatal rats is associated with an upregulation of PARP and NF- $\kappa \mathrm{B}$ and subsequent microgliosis without cell death in the cerebral cortex.

\section{METHODS}

\section{Animal Preparation}

Animals were studied with the approval of the Institutional Animal Care and Use Committee of the University of Minnesota. SpragueDawley P3-P13 female rats were used in the experiments. Pregnant dams were purchased (Harlan Sprague Dawley, Indianapolis, IN) and allowed to deliver spontaneously. Litter size was culled to 8-10 soon after birth. Only female pups were used due to the known sex-specific effects of PARP-1 in brain injury (35).

\section{Induction of Recurrent Hypoinsulinemic Hyperglycemia}

Pups were subjected to hyperglycemia of $2 \mathrm{~h}$ duration twice daily from P3 to P12 (total, 20 episodes). This was done to mimic the intermittent hyperglycemia in ELBW infants, which often lasts for several hours each day over several days, as mentioned earlier $(36,37)$. Furthermore, we also based our model on an earlier study that showed an intermittent hyperglycemia animal protocol was associated with evidence of oxidative stress in the brain regions (21). Hyperglycemia in human neonates is characterized by hypoinsulinemia/insulin insensitivity, whereas induction of hyperglycemia in healthy animals would stimulate insulin secretion. To mimic the hypoinsulinemic-hyperglycemia seen in human neonates, somatostatin analog, octreotide (Novartis Pharmaceuticals Corporation, East Hanover, NJ) was used to suppress endogenous insulin secretion during hyperglycemia.

Pups were separated from the dams and subcutaneously injected with $100 \mu \mathrm{g} / \mathrm{kg}$ of octreotide at $0 \mathrm{~h}$, followed by $30 \%$ dextrose (Hospira, Lake Forest, IL) at 0 and $1 \mathrm{~h}$ injected at the nape of the neck in a dose of $3.5 \mathrm{mg} / \mathrm{g}$ s.c. Littermates in the control group were similarly fasted and injected with octreotide and an equivalent volume of $0.9 \%$ saline at 0 and $1 \mathrm{~h}$. All rats were maintained at the nesting temperature of $34.0 \pm 1.0^{\circ} \mathrm{C}$ without access to food. Blood glucose concentrations were measured at 1 and $2 \mathrm{~h}$ in blood samples obtained from the tail vein using commercial strips (Roche Diagnostics, Indianapolis, IN). Pups were returned to dams at the conclusion of the $2 \mathrm{~h}$ observation period. Blood glucose was measured $1 \mathrm{~h}$ later in representative pups from each litter to confirm resolution of hyperglycemia. 


\section{Tissue Preparation}

Rats were killed on P13, $12 \mathrm{~h}$ after the last episode of hyperglycemia using an overdose of sodium pentobarbital ( $100 \mathrm{mg} / \mathrm{kg}$, i.p.). The brain was removed and the cerebral cortex was quickly dissected on ice, flash-frozen using liquid nitrogen and stored at $-80{ }^{\circ} \mathrm{C}$ until analysis. Rats used for histochemistry ( $n=4-6$ per group) underwent in situ transcardial perfusion-fixation before removal of brain as previously described (40).

\section{Quantitative RT-PCR (qPCR)}

Experiments were performed as previously described $(n=5-7)$ (39). Total RNA was isolated using an RNA isolation kit (MO BIO Laboratories, Carlsbad, CA) and cDNA was generated using $500 \mathrm{ng}$ of RNA (Stratagene, La Jolla, CA). The qPCR experiments were performed using $4 \mu \mathrm{l}$ of diluted cDNA and $0.5 \mu \mathrm{l} 20 \times$ primer/probe (Applied Biosystems, Foster City, CA). Each sample was assayed in duplicate and was normalized against ribosomal protein S18.

\section{Western Analysis}

Concentrations of PAR, NF- $\kappa \mathrm{B}$, and I $\mathrm{BB}$ in the cortex were determined using published methods $(n=4-5)$ (40). Cortical brain tissue was separated into nuclear and cytosolic fractions. After tissue homogenization, cells were resuspended in buffer containing 0.5 $\mathrm{mmol} / \mathrm{l}$ phenylmethylsulfonyl fluoride and incubated for $15 \mathrm{~min}$ on ice. Cytosolic fraction separated with centrifugation for $30 \mathrm{~min}$ at $4{ }^{\circ} \mathrm{C}$ and $11,000 \mathrm{rpm}$. Subsequent resuspension in $5 \mathrm{mmol} / \mathrm{l}$ phenylmethylsulfonyl fluoride buffer and centrifugation separated the nuclear fraction. Western blot was performed using twenty $\mu \mathrm{g}$ of protein and primary antibodies against PAR (1:1,000; Enzo Life Sciences,

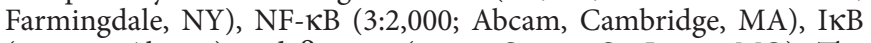
$(1: 5,000 ;$ Abcam $)$ and $\beta$-actin (1:500; Sigma, St. Louis, MO). The bound antibodies were visualized (Vector Laboratories, Burlingame, $\mathrm{CA}$ ) and the intensity of protein relative to $\beta$-actin was determined.

\section{Immunohistochemistry}

Degenerating cells were stained in the cerebral cortex using Fluoro Jade-B as in previous studies (40). All positive cells from one section per animal were counted manually. CD-11 immunohistochemistry was performed as previously described (32). The protein/antibody complex was visualized using a chromagen kit (Vector Laboratories). All CD11 cells were counted in two sections (right and left medial cortex) per animal of equal area and position. Total cells $/ \mathrm{mm}^{2}$ were calculated.

\section{Statistical Analysis}

Data are reported as mean \pm SEM. All comparisons were specified a priori. Unpaired $t$-tests were used to compare control and hyperglycemia groups (GraphPad Prism, La Jolla, CA). Statistical significance was accepted at $P<0.05$.

\section{STATEMENT OF FINANCIAL SUPPORT}

Funding for this project was provided by a grant from the Vikings Children's Fund.

Disclosures: The authors report no conflicts of interest.

\section{REFERENCES}

1. Hey E. Hyperglycaemia and the very preterm baby. Semin Fetal Neonatal Med 2005;10:377-87.

2. Hays SP, Smith EO, Sunehag AL. Hyperglycemia is a risk factor for early death and morbidity in extremely low birth-weight infants. Pediatrics 2006;118:1811-8.

3. Kao LS, Morris BH, Lally KP, Stewart CD, Huseby V, Kennedy KA. Hyperglycemia and morbidity and mortality in extremely low birth weight infants. J Perinatol 2006;26:730-6.

4. Hall NJ, Peters M, Eaton S, Pierro A. Hyperglycemia is associated with increased morbidity and mortality rates in neonates with necrotizing enterocolitis. J Pediatr Surg 2004;39:898-901; discussion 898-901.

5. Ramel SE, Long JD, Gray H, Durrwachter-Erno K, Demerath EW, Rao R. Neonatal hyperglycemia and diminished long-term growth in very low birth weight preterm infants. J Perinatol 2013;33:882-6.
6. Perantie DC, Lim A, Wu J, et al. Effects of prior hypoglycemia and hyperglycemia on cognition in children with type 1 diabetes mellitus. Pediatr Diabetes 2008;9:87-95.

7. van der Lugt NM, Smits-Wintjens VE, van Zwieten PH, Walther FJ. Short and long term outcome of neonatal hyperglycemia in very preterm infants: a retrospective follow-up study. BMC Pediatr 2010;10:52.

8. Szabó C, Zingarelli B, O'Connor M, Salzman AL. DNA strand breakage, activation of poly (ADP-ribose) synthetase, and cellular energy depletion are involved in the cytotoxicity of macrophages and smooth muscle cells exposed to peroxynitrite. Proc Natl Acad Sci USA 1996;93:1753-8.

9. Kiss L, Szabó C. The pathogenesis of diabetic complications: the role of DNA injury and poly(ADP-ribose) polymerase activation in peroxynitritemediated cytotoxicity. Mem Inst Oswaldo Cruz 2005;100 Suppl 1:29-37.

10. Chiarugi A, Moskowitz MA. Cell biology. PARP-1-a perpetrator of apoptotic cell death? Science 2002;297:200-1.

11. Baker RG, Hayden MS, Ghosh S. NF- $\kappa B$, inflammation, and metabolic disease. Cell Metab 2011;13:11-22.

12. Wang T, Zhang X, Li JJ. The role of NF-kappaB in the regulation of cell stress responses. Int Immunopharmacol 2002;2:1509-20.

13. Adaikalakoteswari A, Rema M, Mohan V, Balasubramanyam M. Oxidative DNA damage and augmentation of poly(ADP-ribose) polymerase/nuclear factor-kappa B signaling in patients with type 2 diabetes and microangiopathy. Int J Biochem Cell Biol 2007;39:1673-84.

14. Zheng L, Szabó C, Kern TS. Poly(ADP-ribose) polymerase is involved in the development of diabetic retinopathy via regulation of nuclear factorkappaB. Diabetes 2004;53:2960-7.

15. Chiarugi A, Moskowitz MA. Poly(ADP-ribose) polymerase-1 activity promotes NF-kappaB-driven transcription and microglial activation: implication for neurodegenerative disorders. J Neurochem 2003;85:306-17.

16. Garcia Soriano F, Virág L, Jagtap P, et al. Diabetic endothelial dysfunction: the role of poly(ADP-ribose) polymerase activation. Nat Med 2001;7: $108-13$.

17. Klein JP, Waxman SG. The brain in diabetes: molecular changes in neurons and their implications for end-organ damage. Lancet Neurol 2003;2: $548-54$.

18. Rice D, Barone S Jr. Critical periods of vulnerability for the developing nervous system: evidence from humans and animal models. Environ Health Perspect 2000;108 Suppl 3:511-33.

19. Kuchmerovska T, Shymanskyy I, Donchenko G, Kuchmerovskyy M, Pakirbaieva L, Klimenko A. Poly(ADP-ribosyl)ation enhancement in brain cell nuclei is associated with diabetic neuropathy. J Diabetes Complications 2004;18:198-204.

20. Yu SW, Wang H, Poitras MF, et al. Mediation of poly(ADP-ribose) polymerase-1-dependent cell death by apoptosis-inducing factor. Science 2002;297:259-63.

21. Tayman C, Yis U, Hirfanoglu I, Oztekin O, Göktaş G, Bilgin BC. Effects of hyperglycemia on the developing brain in newborns. Pediatr Neurol 2014;51:239-45.

22. Rao AR, Quach H, Smith E, Vatassery GT, Rao R. Changes in ascorbate, glutathione and $\alpha$-tocopherol concentrations in the brain regions during normal development and moderate hypoglycemia in rats. Neurosci Lett 2014;568:67-71.

23. Hassa PO, Hottiger MO. A role of poly (ADP-ribose) polymerase in NFkappaB transcriptional activation. Biol Chem 1999;380:953-9.

24. Huang Z, Huang PL, Panahian N, Dalkara T, Fishman MC, Moskowitz MA. Effects of cerebral ischemia in mice deficient in neuronal nitric oxide synthase. Science 1994;265:1883-5.

25. Eizirik DL, Flodström M, Karlsen AE, Welsh N. The harmony of the spheres: inducible nitric oxide synthase and related genes in pancreatic beta cells. Diabetologia 1996;39:875-90.

26. Tanaka J, Qiang L, Banks AS, et al. Foxo1 links hyperglycemia to LDL oxidation and endothelial nitric oxide synthase dysfunction in vascular endothelial cells. Diabetes 2009;58:2344-54.

27. Du XL, Edelstein D, Dimmeler S, Ju Q, Sui C, Brownlee M. Hyperglycemia inhibits endothelial nitric oxide synthase activity by posttranslational modification at the Akt site. J Clin Invest 2001;108:1341-8. 
28. Yang G, Abate A, George AG, Weng YH, Dennery PA. Maturational differences in lung NF-kappaB activation and their role in tolerance to hyperoxia. J Clin Invest 2004;114:669-78.

29. Kreutzberg GW. Microglia: a sensor for pathological events in the CNS. Trends Neurosci 1996;19:312-8.

30. Tikka T, Fiebich BL, Goldsteins G, Keinanen R, Koistinaho J. Minocycline, a tetracycline derivative, is neuroprotective against excitotoxicity by inhibiting activation and proliferation of microglia. J Neurosci 2001;21: 2580-8.

31. Madinier A, Bertrand N, Mossiat C, et al. Microglial involvement in neuroplastic changes following focal brain ischemia in rats. PLoS One 2009;4:e8101.

32. Rao R, Sperr D, Ennis K, Tran P. Postnatal age influences hypoglycemiainduced poly(ADP-ribose) polymerase-1 activation in the brain regions of rats. Pediatr Res 2009;66:642-7.

33. Katkhuda R, Peterson ES, Roghair RD, Norris AW, Scholz TD, Segar JL. Sex-specific programming of hypertension in offspring of late-gestation diabetic rats. Pediatr Res 2012;72:352-61.
34. Hagberg H, Wilson MA, Matsushita $\mathrm{H}$, et al. PARP-1 gene disruption in mice preferentially protects males from perinatal brain injury. J Neurochem 2004;90:1068-75.

35. Won SJ, Yoo BH, Kauppinen TM, et al. Recurrent/moderate hypoglycemia induces hippocampal dendritic injury, microglial activation, and cognitive impairment in diabetic rats. J Neuroinflammation 2012;9:182.

36. Beardsall K, Vanhaesebrouck S, Ogilvy-Stuart AL, et al. Early insulin therapy in very-low-birth-weight infants. N Engl J Med 2008;359:1873-84.

37. Beardsall K, Vanhaesebrouck S, Ogilvy-Stuart AL, et al. Prevalence and determinants of hyperglycemia in very low birth weight infants: cohort analyses of the NIRTURE study. J Pediatr 2010;157:715-9.e1-3.

38. Nehlig A, Pereira de Vasconcelos A. Glucose and ketone body utilization by the brain of neonatal rats. Prog Neurobiol 1993;40:163-221.

39. Hagberg H, Bona E, Gilland E, Puka-Sundvall M. Hypoxia-ischaemia model in the 7-day-old rat: possibilities and shortcomings. Acta Paediatr Suppl 1997;422:85-8.

40. Ennis K, Tran PV, Seaquist ER, Rao R. Postnatal age influences hypoglycemia-induced neuronal injury in the rat brain. Brain Res 2008;1224:119-26. 